Article

\title{
Heat Transfer and Pressure Drop in Wavy-Walled Tubes: A Parameter-BASED CFD Study
}

\author{
Malik Muhammad Nauman ${ }^{1, *} \mathbb{C}$, Muhammad Sameer ${ }^{2}$, Murtuza Mehdi ${ }^{3}$, Asif Iqbal ${ }^{1}$ and \\ Zulfikre Esa $^{1}$ \\ 1 Faculty of Integrated Technologies, Universiti Brunei Darussalam, Bandar Seri Begawan BE 1410, Brunei; \\ asif.iqbal@ubd.edu.bn (A.I.); 18m8543@ubd.edu.bn (Z.E.) \\ 2 Department of Mechanical Engineering, Rice University, Houston, TX 77005, USA; \\ muhammad.sameer@rice.edu \\ 3 Department of Mechanical Engineering, NED University of Engineering \& Technology, \\ Karachi 75270, Pakistan; drmurtuza@neduet.edu.pk \\ * Correspondence: malik.nauman@ubd.edu.bn; Tel.: +673-885-1803
}

Received: 13 September 2020; Accepted: 21 October 2020; Published: 9 November 2020

check for updates

\begin{abstract}
Co-relations of friction factor and Nusselt number for plain tubes have been widely developed, but less analysis has been done for tubes with wavy surfaces. This paper uses the Computational Fluid Dynamics (CFD) tool for the analysis of heat transfer and pressure drop in wavy-walled tubes, which can be utilized as a heating element for fluids. An investigation was done for the effect of Reynolds number $(R e)$ and wavy-walled tube geometry on friction factor and Nusselt number of laminar and turbulent flow inside wavy-walled tubes. The numerical results and experimental comparison indicate that heat transfer and pressure drop for water are significantly affected by wavy-walled tube parameters and flow Reynolds number. These wavy-walled tubes are capable of increasing the heat transfer to or from a fluid by an order of magnitude but at an expense of higher pumping power. This ratio was found to remain at the minimum at a wave factor of 0.83 for $34<R e<3500$ and maximum at a wave factor of 0.15 for $200<R e<17,000$. New correlations of friction factor and Nusselt number based on wavy-walled tube parameters are proposed in this paper, which can serve as design equations for predicting the friction factor and heat transfer in wavy-walled tubes under a laminar and turbulent regime with less than $10 \%$ error. The quantitative simulation results match the experimental results with less than $15 \%$ error. The qualitative comparison with the experiments indicates that the simulations are well capable of accurately predicting the circulation zones within the bulgy part of the tubes.
\end{abstract}

Keywords: wavy-walled tubes; Nusselt number; pressure drop; heat transfer; flow separation

\section{Introduction}

Heat transfer can be significantly improved by augmenting the heat transfer area as shown by Takeishi and Beate et al. [1,2]. This augmentation can be done axially to form a tube having a diameter varying sinusoidally, hence forming a wavy-walled tube. Several studies have been conducted on the nature of flow through the tubes with variable cross-sections. Hatami et al. [3] studied the heat transfer of a nanofluid in similar variable cross-section tubes like a venturi and a wavy tube. The authors computed velocity and temperature fields within the tubes and calculated surface Nusselt number to evaluate the heat transfer capability of the venturi and wavy tubes. The rate of heat transfer in laminar flows can be augmented by utilizing such alternatives, which includes using low Prandtl number $(\mathrm{Pr})$ fluids like liquid sodium as shown by Mehdi et al. [4], using nanofluids as shown by Yang et al. [5], and enhancing heat transfer area as indicated by Kim et al. [6]. Sui et al. [7] studied heat 
transfer in wavy microchannels under a laminar flow regime. Dizaji et al. [8] experimentally studied the behavior of corrugated tubes in a double pipe heat exchanger. Their study includes the changing of inner and outer tube orientations of wavy-walled tubes and showed that maximum effectiveness of heat exchanger is achieved by keeping a concave outer tube and convex inner tube. Laohalertdecha and Wongwises [9] experimentally investigated the effect of corrugation pitch on the heat transfer during condensation of R-134 and its pressure drop inside a corrugated tube. They showed that heat transfer and pressure drop through the corrugated tube have higher values than the plain tube for all implemented conditions used in the experiments. Siddiqa and Hossain [10] numerically studied the natural convection that has been induced by the help of two wavy surfaces. They solved the governing equations using the finite difference method and computed the local Nusselt numbers and friction coefficients. The authors showed the rate of heat transfer is dependent on the surface geometry parameters. Sherikar and Disimile [11] performed their analysis on the wavy surface Couette flow. In their analysis, the lower stationary plate is wavy while the upper moving plate is flat, and when compared to the Couette flow of flat plates, they found a significant difference in velocity and stress fields. The authors analyzed the effect of wave amplitude on the turbulent flow characteristics between these plates. Prince et al. [12] studied a tube that is wavy along the circumference but has a uniform cross-section. Arman and Hassanzadeh [13] investigated the heat and fluid flow inside a wavy tube, but the tube they used has a constant diameter cross-section with a wavy central axis, unlike the tube we studied in this study, which had a variable diameter cross-section with a linear central axis; however, we chose similar parameters to determine their effect on the thermo-hydraulic performance of the tubes, like Reynolds number and wavy tube amplitudes and wavelengths. Jin et al. [14] performed an analysis on similar surface augmented tubes, such as spirally corrugated tubes, and showed that tube parameters like pitch and corrugation depth significantly affect the Nusselt number of the flow. Heat transfer performance of such corrugated tubes is increased up to $33 \%$ compared to the plain tubes. Their analysis gave a motivation for enhancing the heat transfer ability of tubes due to the change in the surface geometries. Ramgadia and Saha [15] used a similar sinusoidal wavy tube but with different surface functions for their heat transfer study. They showed that the critical Reynolds number for wavy-walled tubes is significantly affected by their waviness and found it to be much lower than that of the plain tubes. They also studied the friction factor in these tubes and combined it with the Nusselt number to define a thermal performance factor that shows how well the wavy-walled tube is performing thermally compared to the loss in hydrodynamic performance. The authors showed that the thermal performance factor is highest at the highest Reynolds number studied, which is 1000. Muhammad et al. presented numerical techniques to determine state and input, which can be extended to a structure with a wavy-tube-like area by modifying the techniques from Cartesian to polar coordinates and is a good topic of research [16-18]. Pethkool et al. [19] calculated increment in the heat transfer for turbulent flow regime inside a heat exchanger installed with a helically corrugated tube with a corrugated tube as the inner tube of the heat exchanger with a plain tube as the outer tube of the heat exchanger. They presented that friction factor and Nusselt number increased by 2.14 and 3.01 times than the plain tube, respectively. Laohalertdecha et al. [20] analyzed the coefficient of heat transfer and friction factor of two-phase flow during the evaporation of R-134a through a corrugated tube. The test unit was designed with a corrugated tube as an inner tube and a plain tube as an outer tube. They showed relations for the Nusselt number and the friction factor as a function of the Reynolds number, inside diameter, pitch-length, and amplitude of corrugation. Mehdi et al. [21] examined the heat output and pressure drop of liquid sodium having a laminar flow regime through a wavy-walled tube and showed that wave pitch and wave amplitude have a significant effect on heat output while Reynolds number has an insignificant effect on it. Also, the pressure drop is significantly affected by wave amplitude and the Reynolds number. On the other hand, Bian et al. [22,23] experimentally investigated the mass transfer characteristics in wavy-walled tubes. Their results showed that mass transfer and pressure drop increases in a wavy-walled tube 
compared to a plain tube. Furthermore, they showed that mass transfer is higher in a wavy-walled tube than a plain tube under equal pumping power.

To sum up, the above studies had already treated the fluid flow, heat, and mass transfer characteristics in various channels and tubes, but the effects of dimensions of wavy-walled tubes on friction factor and Nusselt number $(\mathrm{Nu})$ have been scarcely explored. In our study, designed a series of wavy-walled tubes with different dimensions, and the effects of tube geometry on the fluid flow and heat transfer characteristics in wavy-walled tubes for laminar and turbulent flow were investigated. The present study provides a significant reference for the design of highly efficient heat exchangers and space heating equipment.

\section{Methodology}

Computational Fluid Dynamics (CFD) analysis was performed on the wavy-walled tubes to determine its heat transfer ability and pressure loss. For that, a wavy-walled tube was designed that has a diameter varying sinusoidally in an axial direction, hence showing a wavy surface. Multiple tubes were designed by changing its parameters in such a way that each tube shows a different level of waviness. These tubes of different waviness are expected to show different behavior towards heat transfer and pressure loss, that is, the one with lower waviness may show lower heat transfer and pressure loss compared to the one with higher waviness.

The tube domain was then discretized in several cells that replicate the continuum fluid field inside the tube. Boundary conditions of a solid no-slip surface are applied on the wavy surface, while the periodic boundary condition was applied on the inlet and outlet surfaces. Instead of solving the whole fluid domain in 3D, only the $2 \mathrm{D}$ domain from the wavy surface to the axis was solved with an axisymmetric boundary condition on the surface representing the central axis of the tube. The approach of using periodic boundary conditions and axisymmetric boundary conditions saved a lot of computation time, otherwise, the whole 3D long tube had to be solved.

Governing equations were solved on the discrete nodes that give the velocity, pressure, and temperature on all the nodes. These properties were then used to determine the heat transfer and pressure drop in a tube, which is discussed in detail later in this paper.

The wavy-walled tube geometry was designed in software Gambit using Equation (1):

$$
r=R+A \cos \left(2 \pi \frac{x}{L}\right)
$$

The schematic of the wavy-walled tube is shown in Figure 1, in which, $A$ is amplitude of wavy-walled tube, $L$ is periodic length of wavy-walled tube, $R$ is mean radius of wavy-walled tube, $r$ is local radius, and $x$ is the position of local radius $(0 \leq x \leq L)$. The waviness of the tube has been expressed by the term wave factor, which can be defined by Equation (2):

$$
F_{w}=\frac{D_{\max }}{D_{\min }} \times \frac{2 A}{L}
$$

where $F_{w}$ is wave factor, $D_{\max }$ is maximum diameter of wavy-walled tube $\left(D_{\max }=2 R+2 A\right), D_{\min }$ is minimum diameter of wavy-walled tube $\left(D_{\min }=2 R-2 A\right)$. The geometries of the wavy-walled tubes used in this paper are presented in Table 1 . All the wavy-walled tube geometries used in this paper have maximum diameter $D_{\max }=10 \mathrm{~mm}$, while the minimum diameter $D_{\min }$ and periodic length $L$ are varied in such a way to form the wave factor ranging from 0.15 to 0.83 . 
Table 1. Dimensions of wavy-walled tubes.

\begin{tabular}{ccccc}
\hline $\boldsymbol{D}_{\text {max }}(\mathbf{m m})$ & $\boldsymbol{D}_{\boldsymbol{\text { min }}}(\mathbf{m m})$ & $\mathbf{2 A}(\mathbf{m m})$ & $\boldsymbol{L}(\mathbf{m m})$ & $\boldsymbol{F}_{\boldsymbol{w}}$ \\
\hline 10 & 7 & 1.5 & 14 & 0.15 \\
10 & 5 & 2.5 & 14 & 0.36 \\
10 & 3 & 3.5 & 20 & 0.58 \\
10 & 3 & 3.5 & 17 & 0.69 \\
10 & 3 & 3.5 & 14 & 0.83 \\
\hline
\end{tabular}

Laminar flow was simulated using the axisymmetric tube shown in Figure 1 with a grid of 28,000 2D fluid cells as shown in Figure 2a. This grid was found to satisfy the criterion for generating a mesh for wall-bounded laminar flows, i.e., the height of the wall-adjacent cell must be less than or equal to the pipe radius divided by thirty-eight (the so-called $R / 38$ rule) [22]. In this work, the maximum height of the wall adjacent cell was $0.00642 \mathrm{~mm}$, which satisfies the meshing criteria for laminar flows.

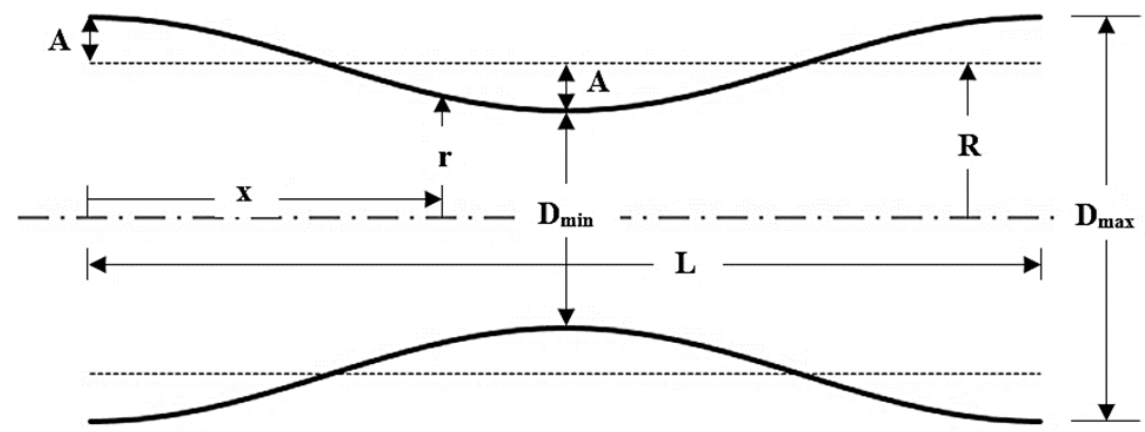

(a)

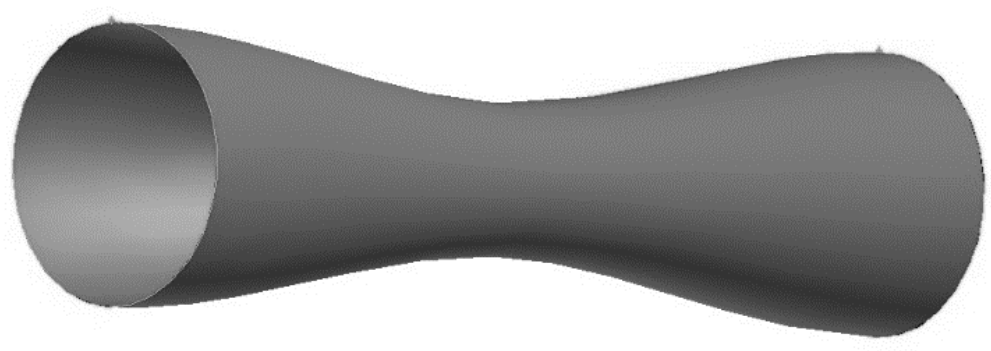

(b)

Figure 1. (a) Geometric variables of the wavy-walled tube and (b) physical view of a single period of the wavy-walled tube.

On the other hand, the turbulent flow was simulated using the same axisymmetric tube geometries with a grid of 100,000 2D fluid cells shown in Figure 2b. This grid was fine enough to resolve the viscous sublayer in the turbulence flow regime, i.e., Near wall cell centroid $Y+<5$. For our case, the maximum $Y+$ was found to be 0.25 for $F_{w}=0.83$ and $R e_{D}=3500$. A magnified view of the grid for turbulent flows is shown in Figure 2c.

Equations (3)-(5) were solved in Ansys Fluent software for the axisymmetric domain shown in Figure 2. A pressure-based solver was used with an axisymmetric domain. Periodic faces were created and mass flow rates were specified to achieve the corresponding Reynolds number. Momentum equation and energy equation were solved using the QUICK scheme, as it is third-order accurate, while the default under-relaxation factors were used. The convergence criteria for all the variables were taken as $1 \times 10^{-6}$, which took an approximate time of $2 \mathrm{~h}$ on a core i5 processor for the solution to converge. 
Momentum Equation:

$$
\rho(\vec{V} . \nabla V)=\nabla \cdot\left[-P I+\mu\left(\nabla \vec{V}+\left(\nabla \vec{V}^{t}\right)\right]-\frac{2}{3} \mu[(\nabla \cdot \vec{V}) I]+F\right.
$$

Continuity Equation:

$$
\nabla \cdot \vec{V}=0
$$

Energy Equation:

$$
\rho C \vec{V} \cdot \nabla T-\nabla \cdot(k \nabla T)=0
$$

where $\rho$ is density of water, $\mu$ is dynamic viscosity of water, $k$ is thermal conductivity of water, $C$ is specific heat of water, $\vec{V}$ the velocity vector, $\nabla$ is del operator, $P$ is pressure of the fluid, $I$ is identity matrix, $t$ represents transpose matrix, and $F$ is the body force. For these simulations, thermophysical properties of water were considered to be constant within a single period of the tube.

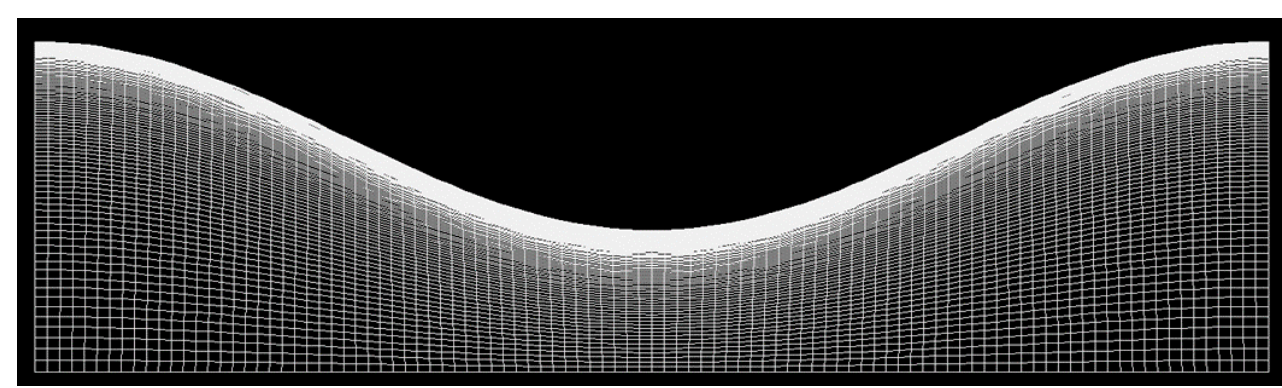

(a)

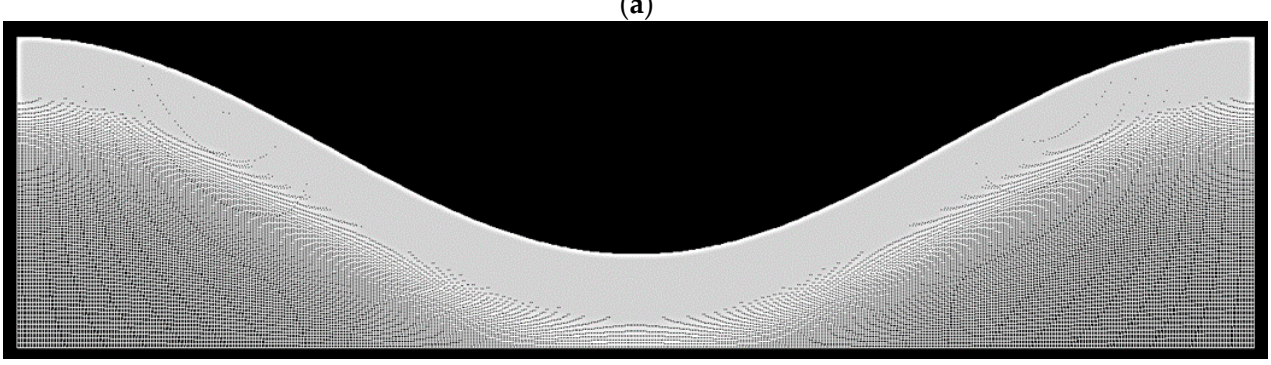

(b)

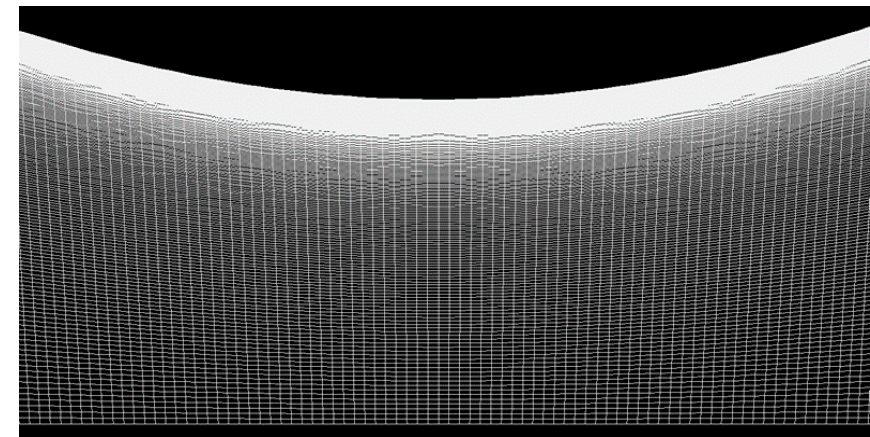

(c)

Figure 2. Typical grid used for the Computational Fluid Dynamics (CFD) computations of (a) laminar and (b) turbulent flow, and (c) magnified view.

When it comes to turbulent flows, other than solving the three governing equations, the equations for turbulence were also needed to be solved. So we faced a choice of turbulence model to be used in this paper. Two-equations models for turbulence were selected, that is $K$ - $\varepsilon$ model and $K$ - $\omega$ model, where $K$ is turbulence kinetic energy, $\varepsilon$ is turbulent kinetic energy dissipation, and wis the specific rate of turbulent kinetic energy dissipation. These two models were tested for the turbulent flow in a plain tube and found that $K$ - $\omega$ shows 
better results than the $K$ - $\varepsilon$ model in predicting the Universal velocity profile, and therefore $K$ - $\omega$ model is further used in this paper for turbulent flow analysis in wavy-walled tubes. Since the geometry under consideration is axisymmetric, the governing Equations (6) and (7) for the $K$ - $\omega$ model were numerically solved for half of the computational domain in the turbulent flow regime.

$$
\begin{gathered}
\rho \frac{\partial k}{\partial t}+\rho U_{j} \frac{\partial k}{\partial x_{j}}=\sigma_{i j} \frac{\partial U_{i}}{\partial x_{j}}-\beta^{*} \rho k \omega+\frac{\partial}{\partial x_{j}}\left[\left(\mu+\sigma_{\omega}{ }^{*} \mu_{T}\right) \frac{\partial k}{\partial x_{j}}\right] \\
\rho \frac{\partial \omega}{\partial t}+\rho U_{j} \frac{\partial \omega}{\partial x_{j}}=\alpha \frac{\omega}{k} \sigma_{i j} \frac{\partial U_{i}}{\partial x_{j}}-\beta \rho \omega^{2}+\frac{\partial}{\partial x_{j}}\left[\left(\mu+\sigma_{\omega} \mu_{T}\right) \frac{\partial \omega}{\partial x_{j}}\right]
\end{gathered}
$$

with $\alpha=0.52, \beta=0.072, \beta^{*}=0.09, \sigma_{\omega}=0.5, \sigma^{*}{ }_{\omega}=0.5$.

Grid independence was tested using three grid sizes $(100,000,200,000$, and 400,000) for wavy-walled tube having $F_{w}=0.58$ and $R e_{D}=1000$. Figure 3a shows the Nusselt number for these grids. It can be noticed that the maximum deviation in the Nusselt number remains up to $1.02 \%$. Also, Figure $3 \mathrm{~b}$ shows the friction factor for these grids. It can be noticed that the maximum deviation in the friction factor remains up to $0.463 \%$. It can be noticed that in each case the deviation remains less than $2 \%$.

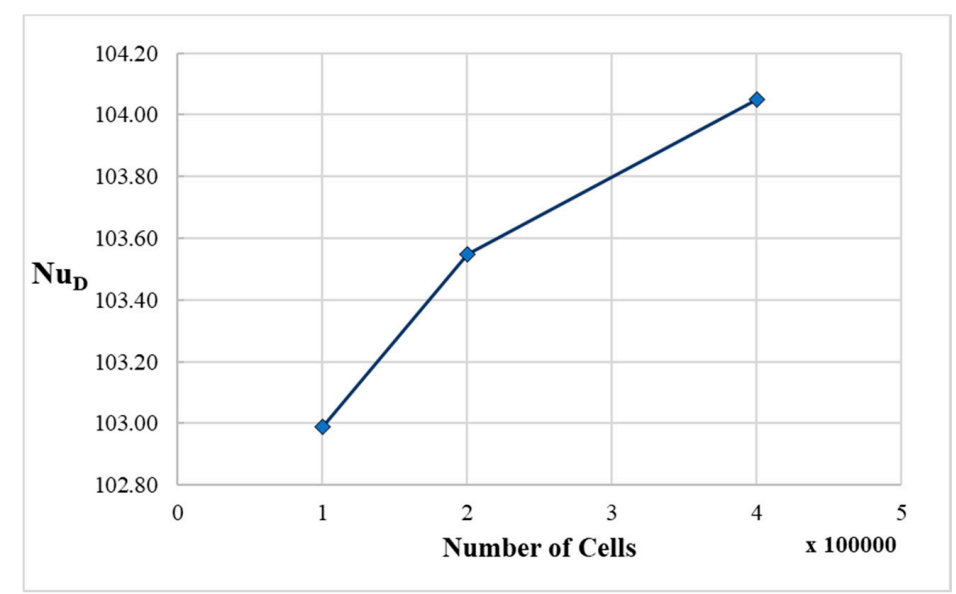

(a)

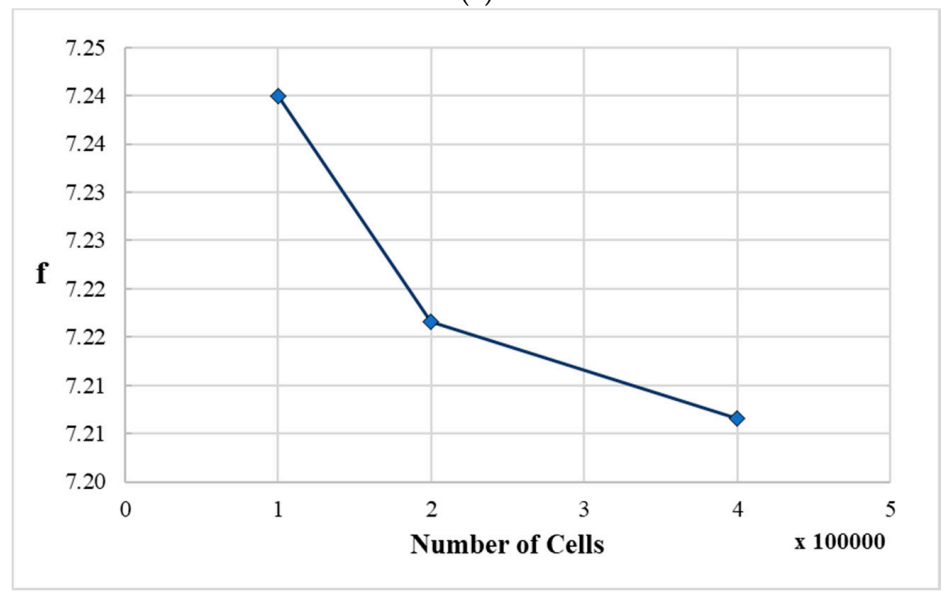

(b)

Figure 3. Grid independence test (a) for Nusselt number and (b) for friction factor.

In this paper, the Reynolds number is defined by Equation (8):

$$
R e_{D}=\frac{4 \dot{m}}{\pi D_{\max } \mu}
$$


where $R e_{D}$ is Reynolds number of the flow (based on the maximum tube diameter $D_{\max }$ ), $\dot{m}$ is mass flow rate of water, $D_{\max }$ is maximum diameter of wavy-walled tube, and $\mu$ is dynamic viscosity of water. Hence mass flow rate was defined on the periodic faces to depict the corresponding Reynolds number. The no-slip condition was defined on the tube wall i.e., $u=0$ at $r=R$, where $u$ is the axial velocity. While for the thermal physics, a constant surface heat flux of $5 \mathrm{~kW} / \mathrm{m}^{2}$ was specified at the tube wall for laminar flow, and a constant surface heat flux of $50 \mathrm{~kW} / \mathrm{m}^{2}$ was specified at the tube wall for turbulent flow. The value of heat flux was such that the boiling of water was avoided. To validate the simulation strategy, experimental work conducted by Yongning Bian et al. [23] was selected. The authors conducted a series of experiments on the flow and mass transfer characterizations of various wavy-walled tubes concerning the Reynolds number. A dimensionless number known as the wave factor $\left(F_{w}\right)$ is defined in their work that was adapted and shown in Equation (2). Note that this single parameter can define the waviness intensity for wavy-walled tubes. A quantitative, as well as qualitative comparison, was done between the CFD results obtained in this paper with the experimental results of Yongning Bian et al. [23].

\section{Results and Discussion}

A total of fifty simulations were performed for five geometries indicated in Table 1 . The range of Reynolds number to be used for simulations has been selected in such a way that three values of the Reynolds number lie in the laminar range and seven values of Reynolds number lie in the turbulent range. The waviness of the tube makes the flow turbulent at the earlier Reynolds number. This relationship of wave factor to critical Reynolds number has been investigated by Yongning Bian et al. [23], which shows the critical Reynolds number can drop up to 160 for the highest wave factor tube $\left(F_{w}=0.83\right)$. For comparison. It is to note that the critical Reynolds number for the plain tube is 2300 .

Iso-surfaces were created in Ansys Fluent software at positions that divide a single period of a wavy-walled tube into 10 segments, hence, eleven iso-surfaces were created on which values of axial velocity were extracted and is shown in Figure 4. Figure 4a shows the velocity profiles for laminar flow hence having a smooth change in velocity gradients, while Figure $4 \mathrm{~b}$ shows velocity profiles for turbulent flows, and hence a sharp change in velocity profiles can be observed near the wall. It can be observed from Figure 4 that there are negative values present in the axial velocity profile that indicates flow reversal. This is because wavy-walled tubes have convergent and divergent sections. Flow separation occurs in the divergent section of the tube that can also be observed from wall shear stress $\left(\tau_{w}\right)$ distribution shown in Figure 5.

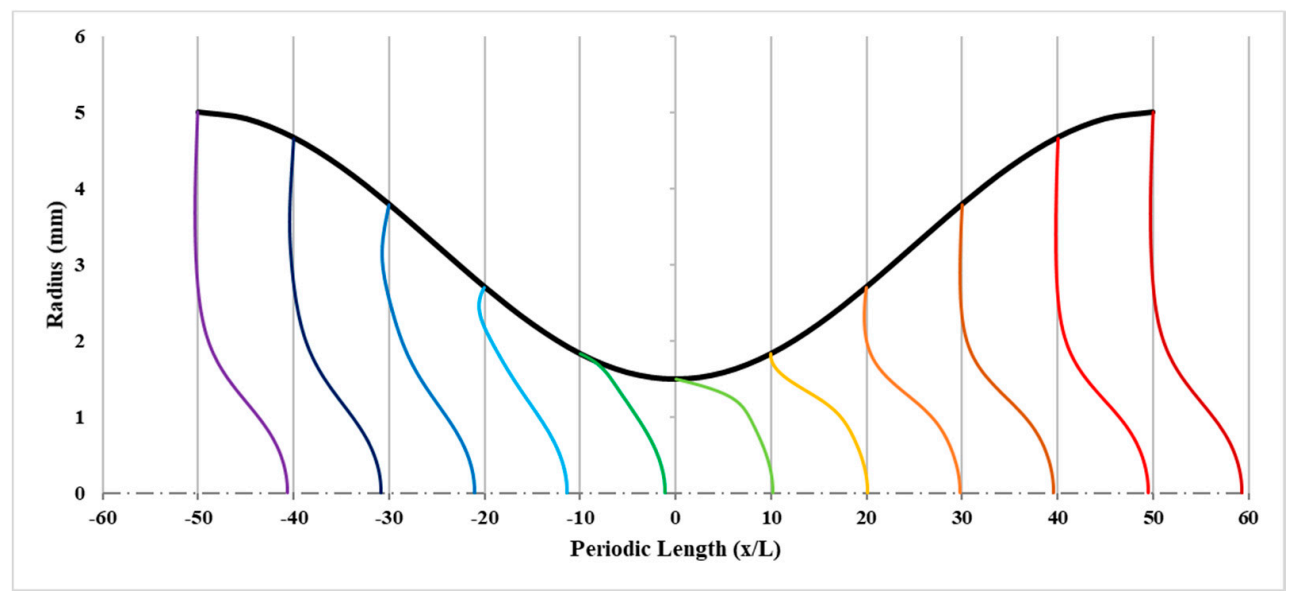

(a)

Figure 4. Cont. 


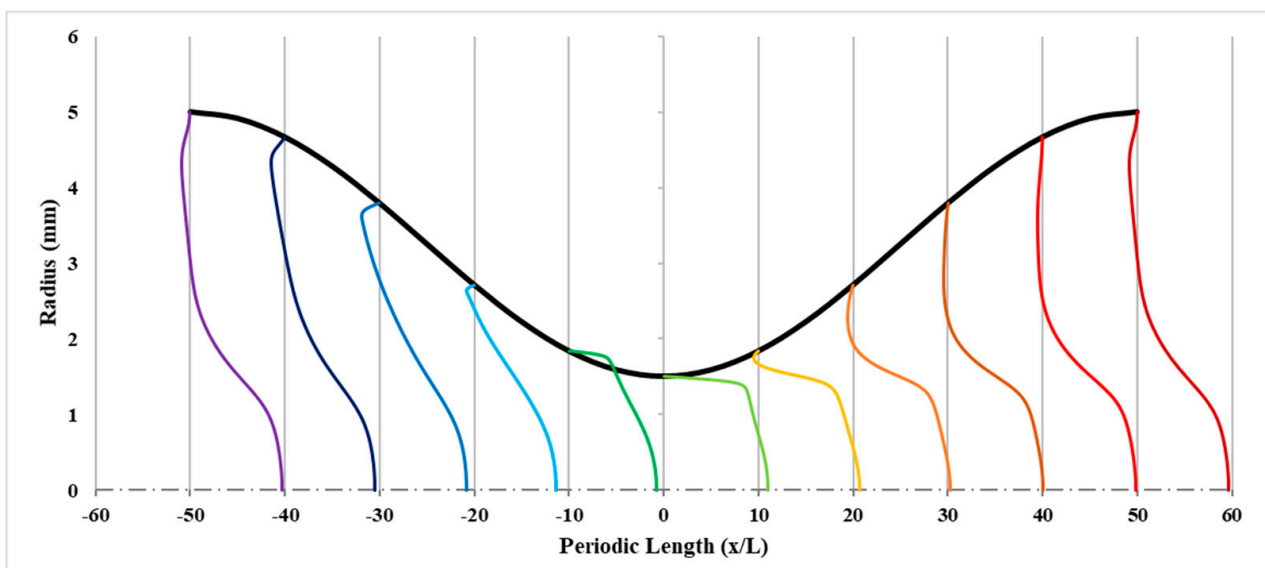

(b)

Figure 4. Velocity profile (scaled) for wavy-walled tube (a) $F_{w}=0.58$ and $R e_{D}=100$ (Laminar) and (b) $F_{w}=0.58$ and $R e_{D}=1000$ (Turbulent).

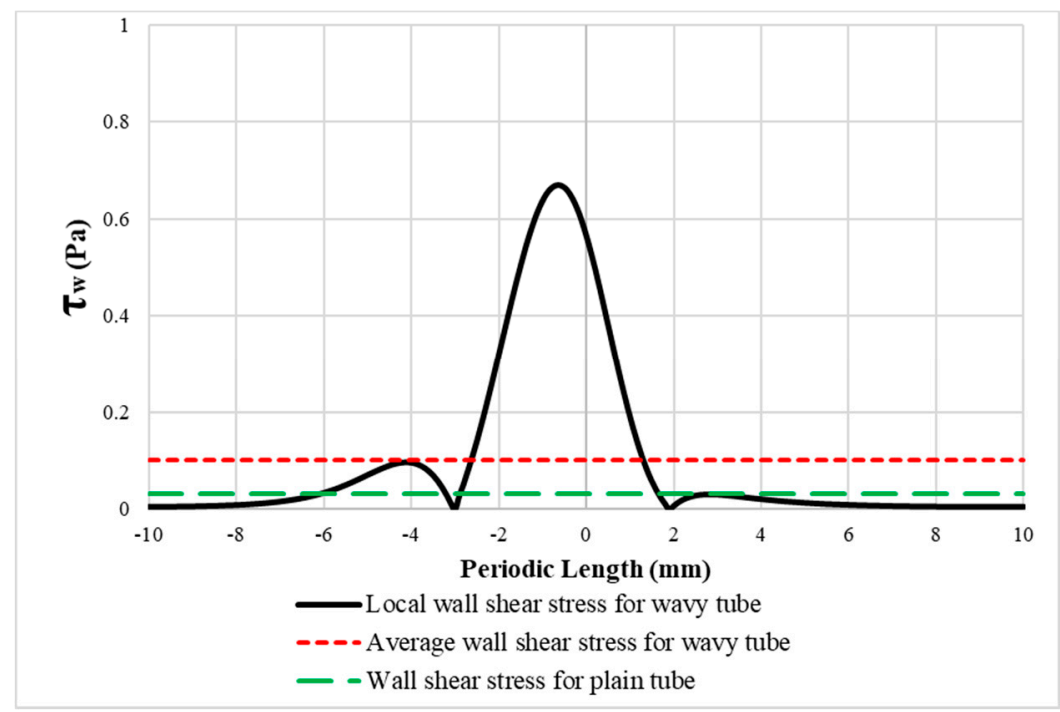

(a)

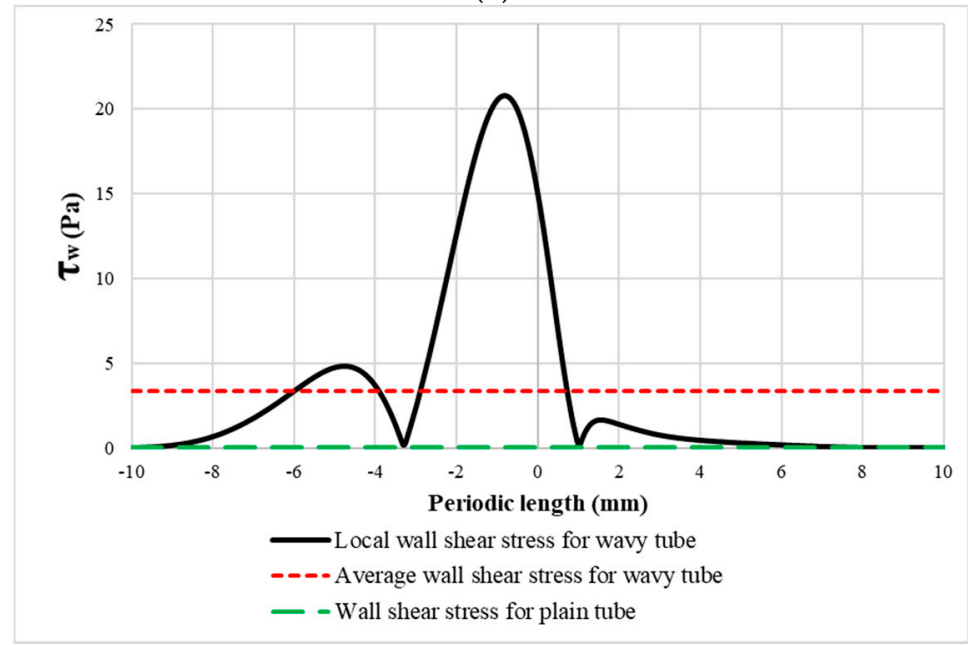

(b)

Figure 5. Wall shear stress distribution for wavy-walled tube (a) $F_{w}=0.58$ and $\operatorname{Re}_{D}=100$ (Laminar) and (b) $F_{w}=0.58$ and $R e_{D}=1000$ (Turbulent). 
It can be seen from Figure 5 that flow separation occurs in the divergent section of the tube, whereas the flow re-attachment occurs in the convergent section. It is to note that shear stress values shown in Figure 5 are the absolute values. The shear stress is showing a peak in the region of minimum diameter due to the high velocity in that region near the wall. As the flow passes that region, it experiences a wide opening and hence flow is separated from the wall. Due to this flow separation, flow reversal takes place and fluid starts flowing in the opposite direction of the bulk flow and starts to form circulation zones. The flow velocity in these circulation zones is very small compared to the bulk flow velocity, therefore creating a relatively lower wall shear stress. This flow characteristic of the wavy-walled tube can also be seen with the help of the streamlines plot in Figure 6 .

A qualitative comparison of the flow characteristics is shown in Figure 6. It can be seen from Figure 6 that the numerical simulations are capable of predicting the circulation zones within the bulgy part of the wavy-walled tube at various Reynolds numbers as noticed in the experiments. Based on these comparisons, it can be concluded that the simulation strategy adopted in this work for the laminar flow inside wavy-walled tubes can be correlated with the experiments with less than $15 \%$ error and thus offers a great deal of prior information regarding the flow characteristics of these complex geometries. As it can be observed from Figure $6 a, c$ which are the actual photographs of the experiments, that the center of the circulation zone is placed in the downstream of the bulgy section, a similar pattern has been observed from the streamlines plot that was obtained from the CFD software and is shown in Figure 6b,d.

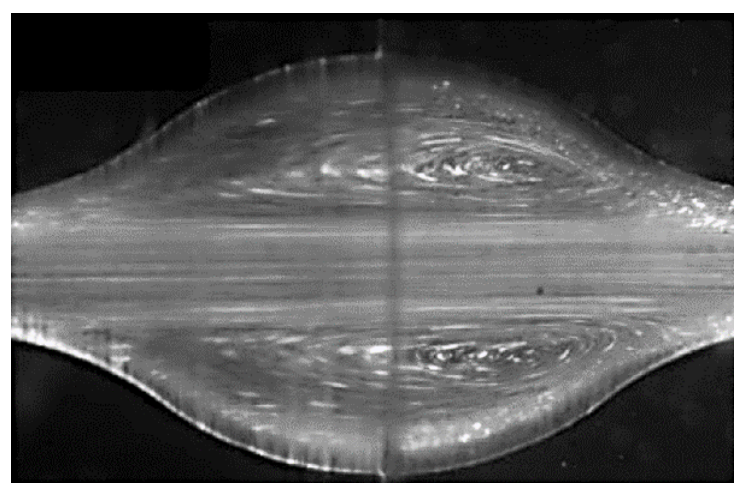

(a)

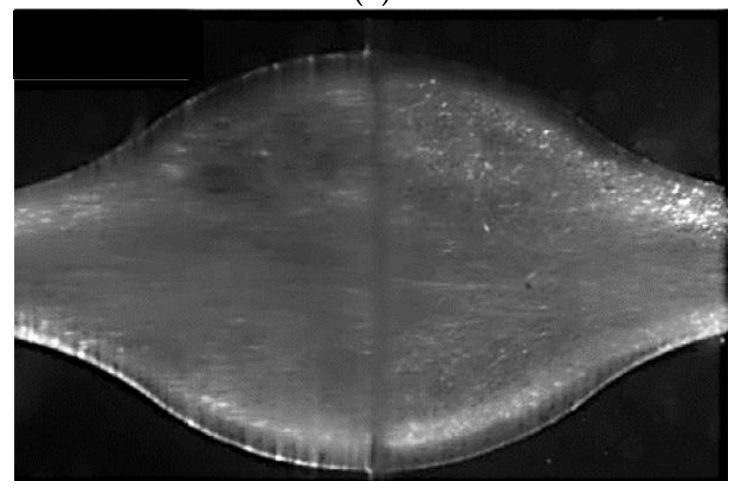

(c)

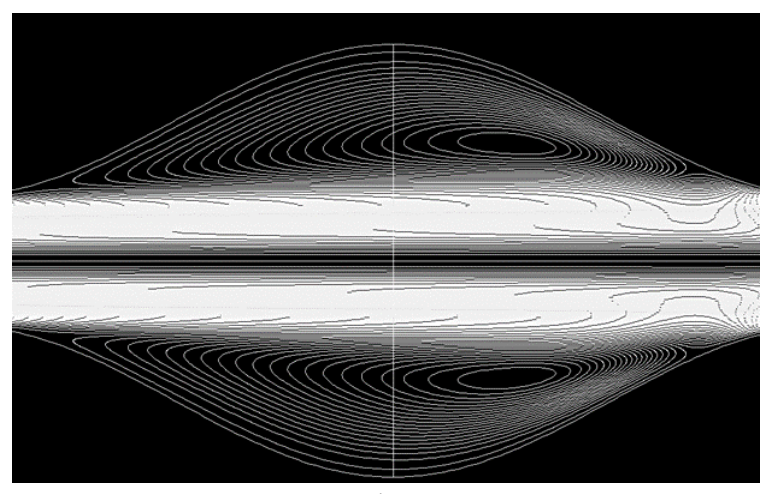

(b)

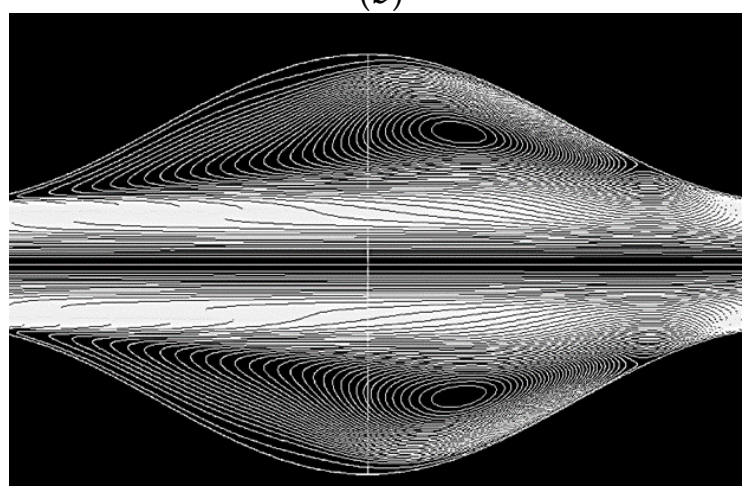

(d)

Figure 6. Qualitative comparison of flow inside the wavy-walled tube (a) Laminar flow pattern inside wavy-walled tube presented by Yongning Bian et al. [21] (b) computed laminar streamlines, (c) turbulent flow pattern inside wavy-walled tube presented by Yongning Bian et al. [21], and (d) computed turbulent streamlines. 
A dimensionless number to represent pressure loss in a tube is Fanning friction factors and can be evaluated using Equation (9):

$$
f=\frac{1}{2} \frac{\frac{\Delta P}{L} D_{\max }}{\rho V_{\text {avg }}^{2}}
$$

where $f$ is Fanning friction factor, $\Delta P / L$ is pressure drop per unit length, $D_{\max }$ is maximum diameter of the tube, $\rho$ is the density of water, and $V_{\text {avg }}$ is the average velocity of water across the tube. Figure 7 depicts the friction factor comparison between the experiments of Yongning et al. and the CFD simulation performed. These simulations show deviated results in the transition region where flow transforms from laminar to turbulent. This is because the $K-\omega$ model is unable to predict the results for transitional flows. But as the Reynolds number increases and flow becomes closer to the fully turbulent regime, the deviation decreases between the experimental and simulated results. While for all of the values of Reynolds number other than transition flow, it can be seen that the numerical results follow the experimental curves with a maximum global error of $14 \%$. It can be seen from Figure 8 that the friction factor in wavy-walled tubes increases with wave factor and in all cases, it remains higher than the plain tube. The higher friction factor in wavy-walled tubes is a consequence of high wall shear stress within the convergent part of the wavy-walled tubes as can be seen in Figure 5.

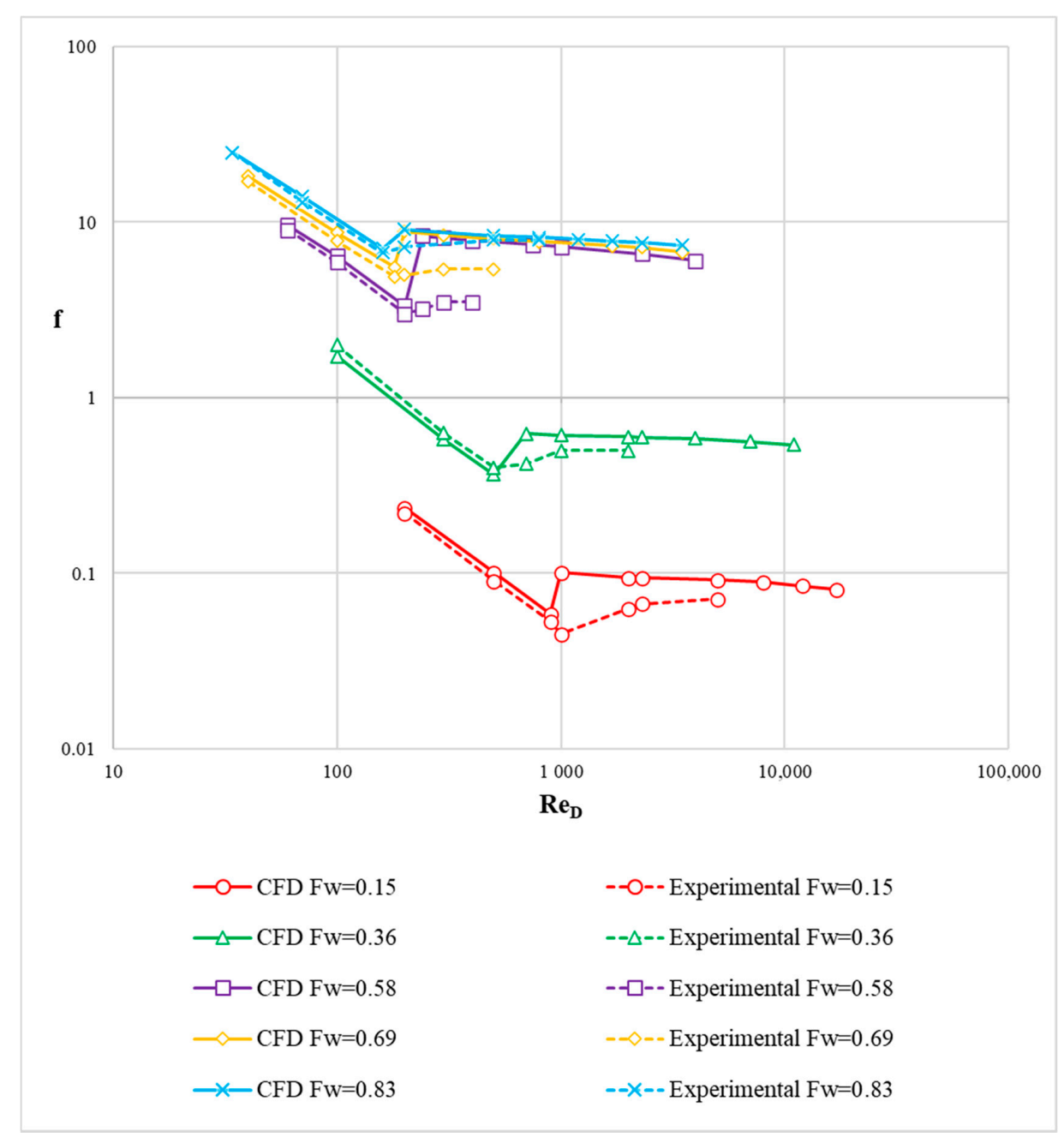

Figure 7. Comparison of experimental and simulated results of friction factor for wavy-walled tubes. 
Figure 8 shows a sudden rise in friction factor. This behavior of friction factor is because when the flow in plain tubes is either in a laminar or turbulent regime, it is a function of Reynolds number. Increasing the Reynolds number would eventually decrease the friction factor. But the interesting part comes when the flow is turbulent, it also becomes a function of pipe surface roughness. Keeping this in mind, the authors used the friction factor behavior for smooth pipe (no roughness) and indicated it by the dark blue line in Figure 8. The same curve can be seen in Moody's chart as well, but the only difference is that Moody's chart has a Darcy friction factor plotted on the $y$-axis while this paper has a Fanning friction factor on the $y$-axis of Figure 8. For clarification, $f^{\prime}=4 f$, where $f^{\prime}$ is Darcy friction factor and $f$ is Fanning friction factor. When the flow regime changes from laminar to turbulent, the friction factor curve shows a sudden increase due to the generation of eddies in the turbulent flow, which results in higher pressure loss and hence higher friction factor. One more reason for this sudden rise in friction factor is that the flow regime has to be strictly either laminar or turbulent when we simulate it numerically, so there would have been a slightly smoother rise in friction factor if we could have simulated the transition flow regime that is between laminar and turbulent ones.

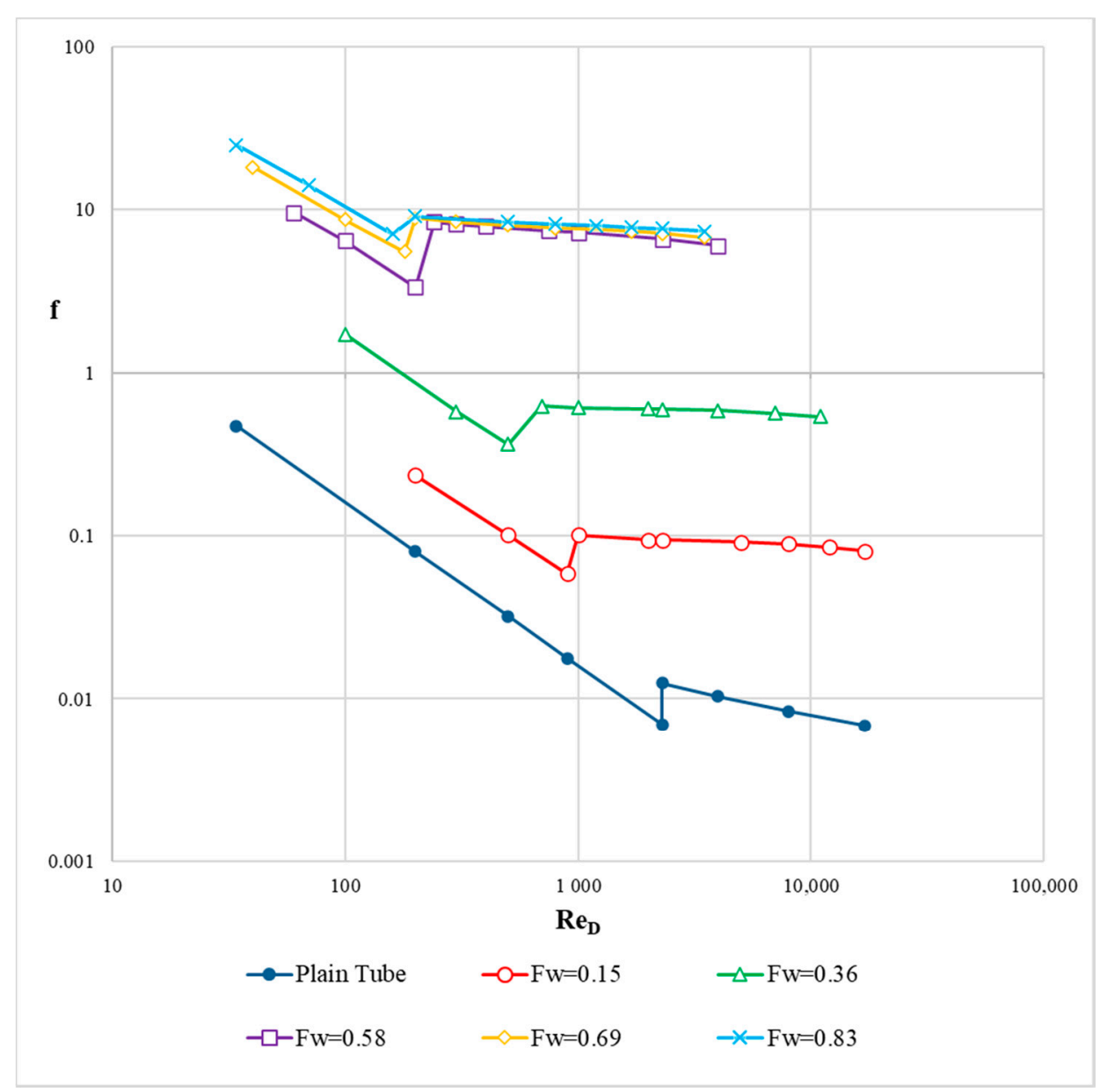

Figure 8. Simulated results of the friction factor for plain and wavy-walled tubes.

This explanation can be used for both the plain tubes and wavy-walled tubes. As for wavy-walled tubes, the transition from laminar to turbulent regime occurs at a much lower Reynolds number compared to the critical Reynolds number of 2300 for plain tubes. This phenomenon can be observed from Figure 8 that the tubes with higher wave factor show transition at lower Reynolds number. Also, higher wave factor tubes offer more pressure loss and hence a higher friction factor.

As it can be seen from Figure 8 that Fanning friction factor for a wavy-walled tube is a function of wave factor and Reynolds number, therefore, a least square method was applied to develop a new 
friction factor correlations that include the effect of Reynolds number and wavy-walled tube parameters, the so-called wave factor. The correlations for laminar and turbulent flows are shown in Equations (10) and (11), respectively. It is to be noted that these correlations can predict the experimental data within a $10 \%$ deviation.

$$
\begin{gathered}
f=\frac{16}{R e_{D}}+\frac{1040 F_{w}^{2.2}}{R e_{D}{ }^{0.9}} \\
f=\frac{37.2 F_{w}^{2.91}}{\operatorname{Re}_{D}{ }^{0.077}}
\end{gathered}
$$

A relationship between the friction factor for wavy-walled tube and plain tube can be formed as shown in Figure 9. It can be seen that as the Reynolds number increases, the friction factor becomes much higher in wavy-walled tubes compared to that of plain tubes. It is because flow becomes turbulent in wavy-walled tubes at a lower Reynolds number than that of plain tubes, hence causing higher friction factor, reaching a maximum value of $f_{w} / f_{p}=1096$ for $F_{w}=0.83$, where $f_{w}$ is friction factor for wavy-walled tube and $f_{p}$ is friction factor for the plain tube. But, as the flow becomes turbulent in plain tubes after $R e_{D}=2300$, the friction factor rises in it, and hence the ratio $f_{w} / f_{p}$ decreases at that instant. After increasing the Reynolds number further, the decrement in the friction factor of the wavy-walled tube is observed to be much lower than that of a plain tube, therefore, $f_{w} / f_{p}$ again tends to increase.

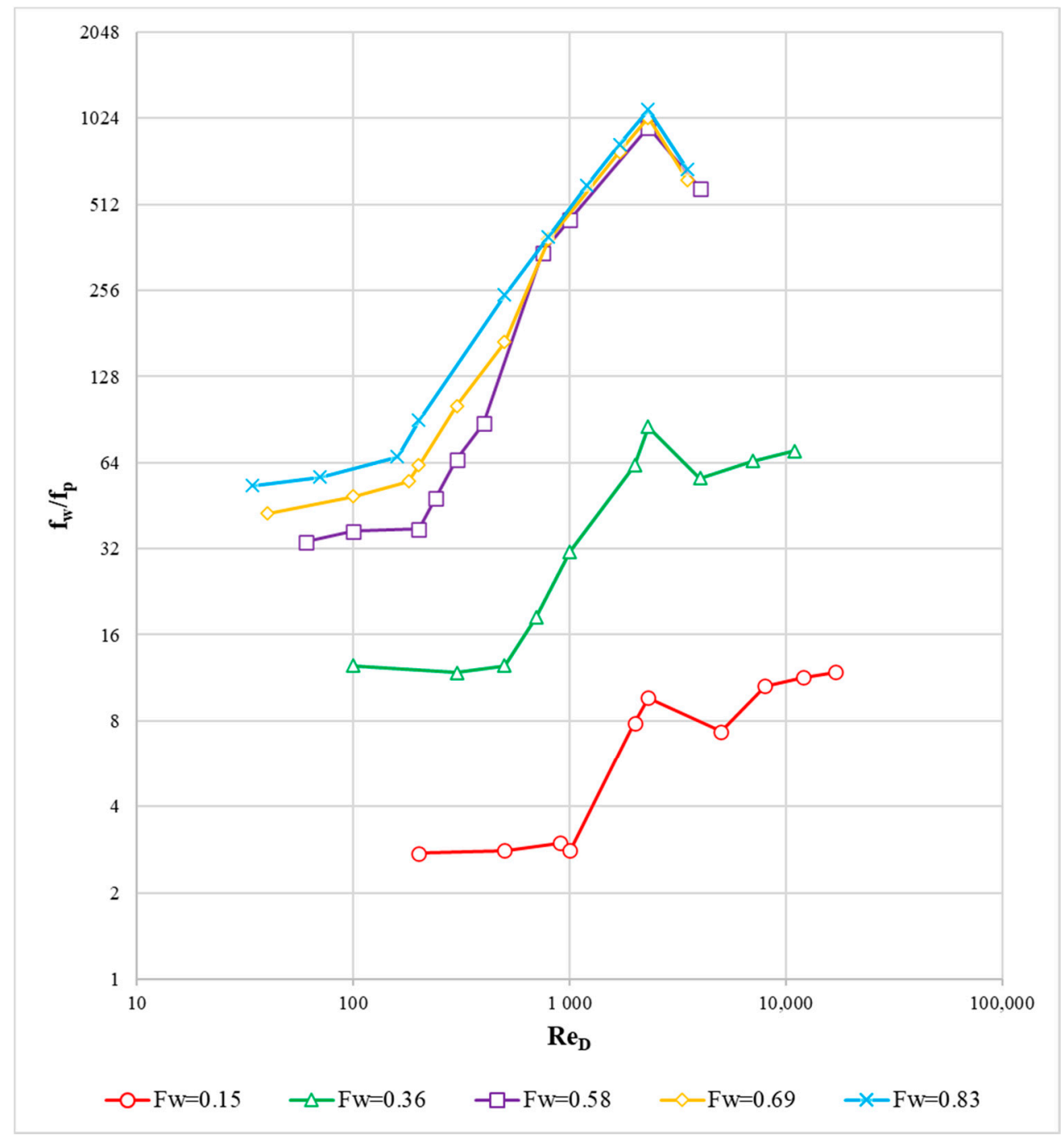

Figure 9. Friction factor increment in wavy-walled tubes. 
For the thermal analysis of these tubes, a dimensionless heat transfer parameter, that is, the Nusselt number, was computed for all the tube geometries. Local Nusselt number distribution along the tube length is shown in Figure 10. It can be seen from Figures 5 and 6 that due to the convergent and divergent sections in the wavy-walled tube, flow separation occurs in the divergent section and then re-attachment occurs in the convergent section, this phenomenon varies the rate of heat transfer along the tube axis. Figure 10 shows that the Nusselt number is highest in the region of lower diameters due to the presence of high velocities in this narrow section that enhances the rate of heat transfer. It is because flow with high velocity can carry the heat much faster compared to low velocity, and hence, the Nusselt number increases. Similarly, when the flow starts to detach from the tube wall in the divergent section, the circulation of the fluid takes place due to which fluid accumulates in the bulgy part of the tube. Since the fluid velocity in the circulation zone is much lower than the bulk fluid velocity in the region around the central axis of the tube, heat transfer is resisted in that bulgy region. This is why the Nusselt number plot shown in Figure 10 has a peak in the center, which is the narrow region and then suddenly drops when the flow starts to separate in the bulgy region of the wavy-walled tube. It is worth noting that the local Nusselt number for wavy-walled tubes is always higher than the plain tube, even in the region where it is lowest. This shows a primary benefit of using these tubes over the plain tubes. The local Nusselt number in this work is calculated using Equation (12).

$$
N u_{x}=\frac{q_{w}{ }^{\prime \prime} D_{\max }}{k\left(T_{w}-T_{b}\right)_{x}}
$$

where; $N u_{x}$ is the local Nusselt number, $q_{w}$ " is the wall heat flux, $k$ is the fluid thermal conductivity, $T_{w}$ is wall surface temperature, $T_{b}$ is bulk temperature of fluid, $\left(T_{w}-T_{b}\right)_{x}$ is the local difference between wall temperature, and bulk fluid temperature and $D_{\max }$ is the maximum diameter of the tube. Bulk fluid temperature can be computed from FLUENT by using a mass-weighted average in the surface integrals tab, while wall temperature across the tube length can be computed from FLUENT using the $\mathrm{XY}$ plot on the wall surface.

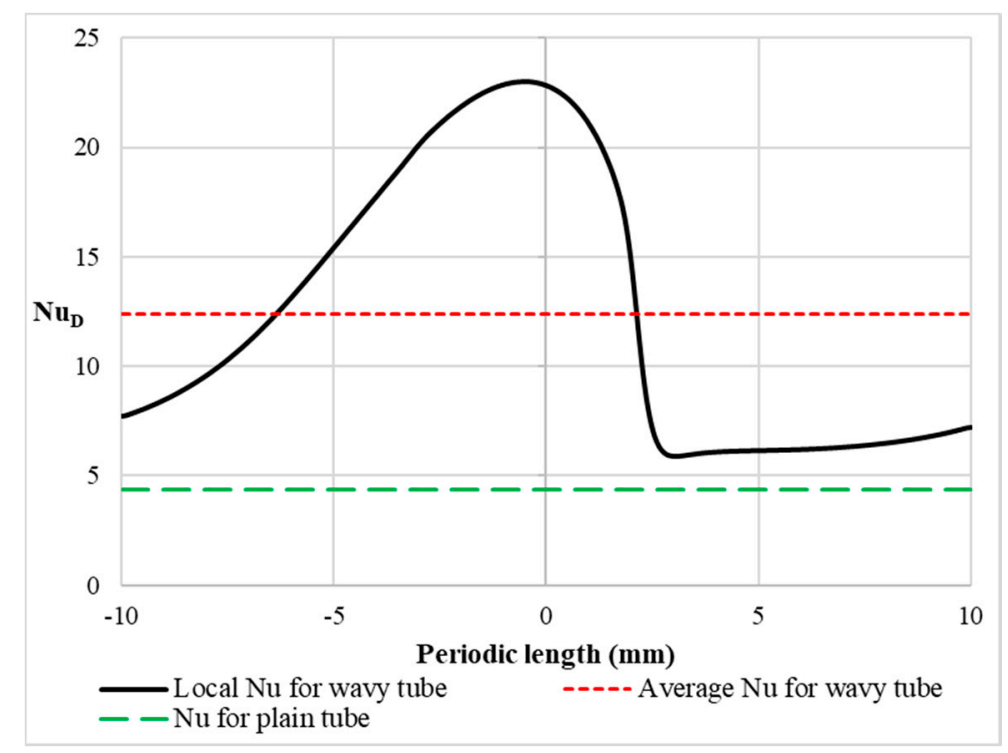

(a)

Figure 10. Cont. 


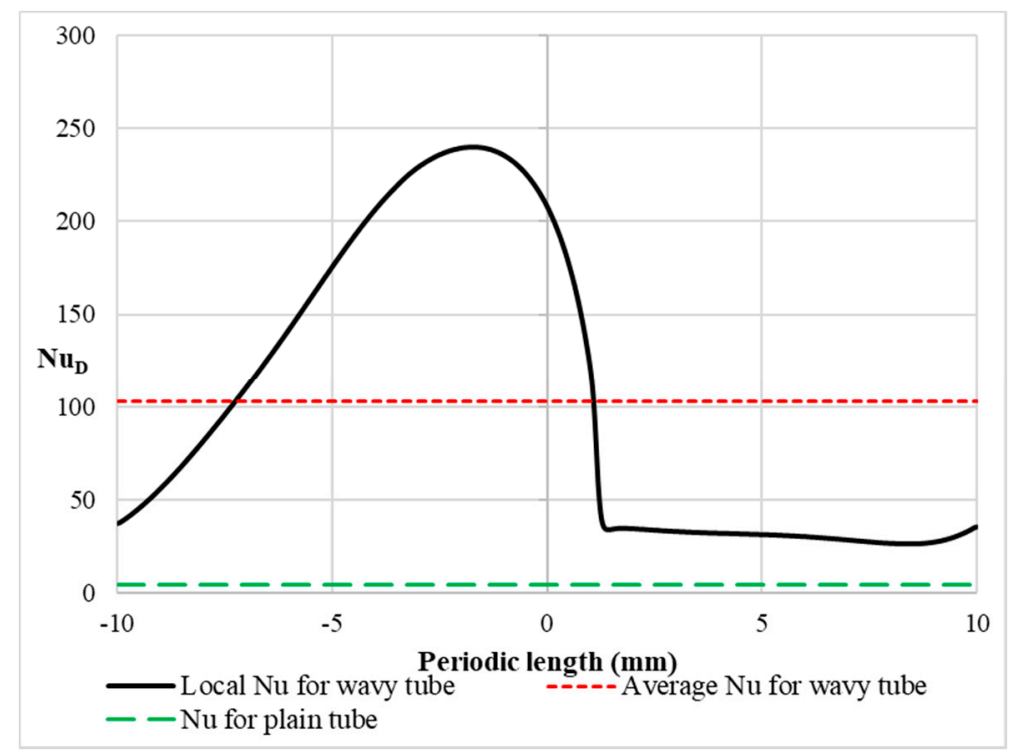

(b)

Figure 10. Local Nusselt number across wavy-walled tube (a) $F_{w}=0.58$ and $R e_{D}=100$ (Laminar) and (b) $F_{w}=0.58$ and $\operatorname{Re}_{D}=1000$ (Turbulent).

The average Nusselt number $N u_{D}$ (based on the maximum tube diameter $D_{\max }$ ) of the wavy-walled tube can be defined by Equation (13). It can be obtained by summing the product of the local Nusselt number and the local differential surface area divided by the total surface area of the tube.

$$
N u_{D}=\frac{1}{A_{s}} \sum_{-L / 2}^{+L / 2} N u_{x} \Delta A_{s}
$$

where $N u_{D}$ is the average Nusselt number of the wavy-walled tube, $A_{s}$ is total surface area of the tube, $N u_{x}$ is local Nusselt number, $L$ is periodic length of wavy-walled tube, and $\Delta A_{s}$ is local differential surface area. Hence, the variation of average Nusselt number with Reynolds number and tube geometry is shown in Figure 11.

Some interesting observations can be made from Figure 11 for laminar flow. For instance, on average it can be seen that even though the Reynolds number remains low, the values of the Nusselt number remain on the higher side when the wave factor reaches and exceeds the value of 0.58 . On the other hand, the Nusselt number reaches its peak value when the wave factor is 0.83 , i.e., 4.39 times higher than the Nusselt number for the plain tube. However, this happens at a relatively higher value of the Reynolds number which ultimately demands higher pumping power. These trends suggest that large values of the wave factor can augment heat transfer effects in high Prandtl number liquids (for instance water) even at moderate values of the Reynolds number. For the turbulent flow, the Nusselt number increases with wave factor and Reynolds number. But only a slight increment has been observed in the Nusselt number for the wave factor beyond 0.58 . 


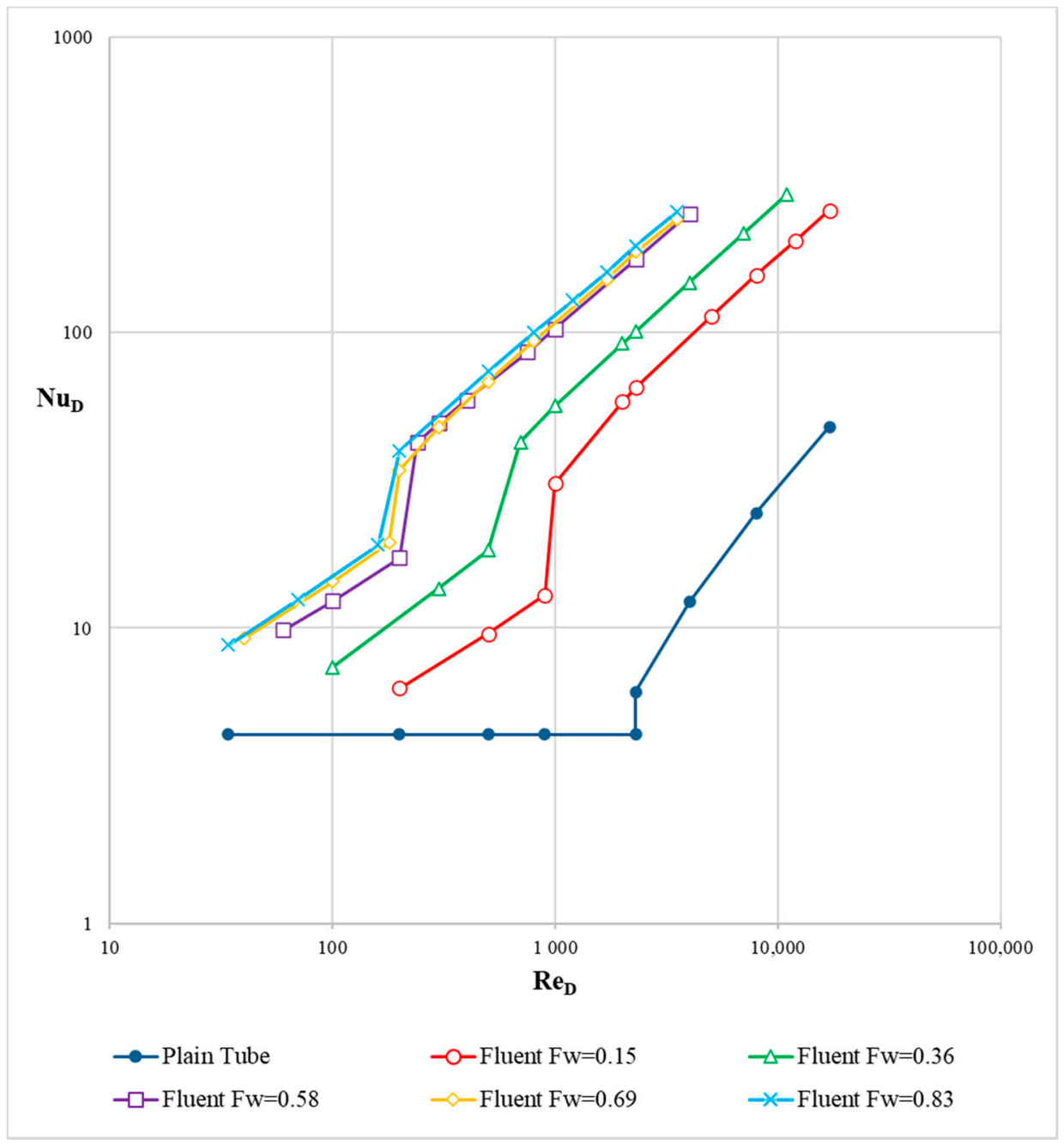

Figure 11. Averaged Nusselt number as a function of Reynolds number and wave factor.

It can be seen from Figure 11 that the Nusselt number for a wavy-walled tube is a function of wave factor and Reynolds number. Therefore, the least square method was applied to develop a new Nusselt number correlations that take account of the Reynolds number and wavy-walled tube parameters, the so-called wave factor. These correlations for laminar and turbulent regimes are shown in Equations (14) and (15), respectively. It is to be noted that these correlations can predict the CFD data within a $10 \%$ deviation.

$$
\begin{gathered}
N u_{D}=4.364+0.3 R e_{D}{ }^{0.85} F_{w}{ }^{1.35} \\
N u_{D}=1.3 \operatorname{Re}_{D}{ }^{0.675} F_{w}{ }^{0.72}
\end{gathered}
$$

Since heat and mass transfer undergo the same physical phenomenon, Figure 12 was also found to show a similar trend that has been presented by Bian et al. [23] for the variation of $S h / S c^{1 / 3}$ with respect to the Reynolds number. These trends can be compared by plotting a relationship between $\mathrm{Nu} / \mathrm{Pr}^{1 / 3}$ to the Reynolds number shown in Figure 12, where the Nusselt number $(\mathrm{Nu})$ is analogous to the Sherwood number $(S h)$, and the Prandtl number $(P r)$ is analogous to the Schmidt number $(S c)$. 


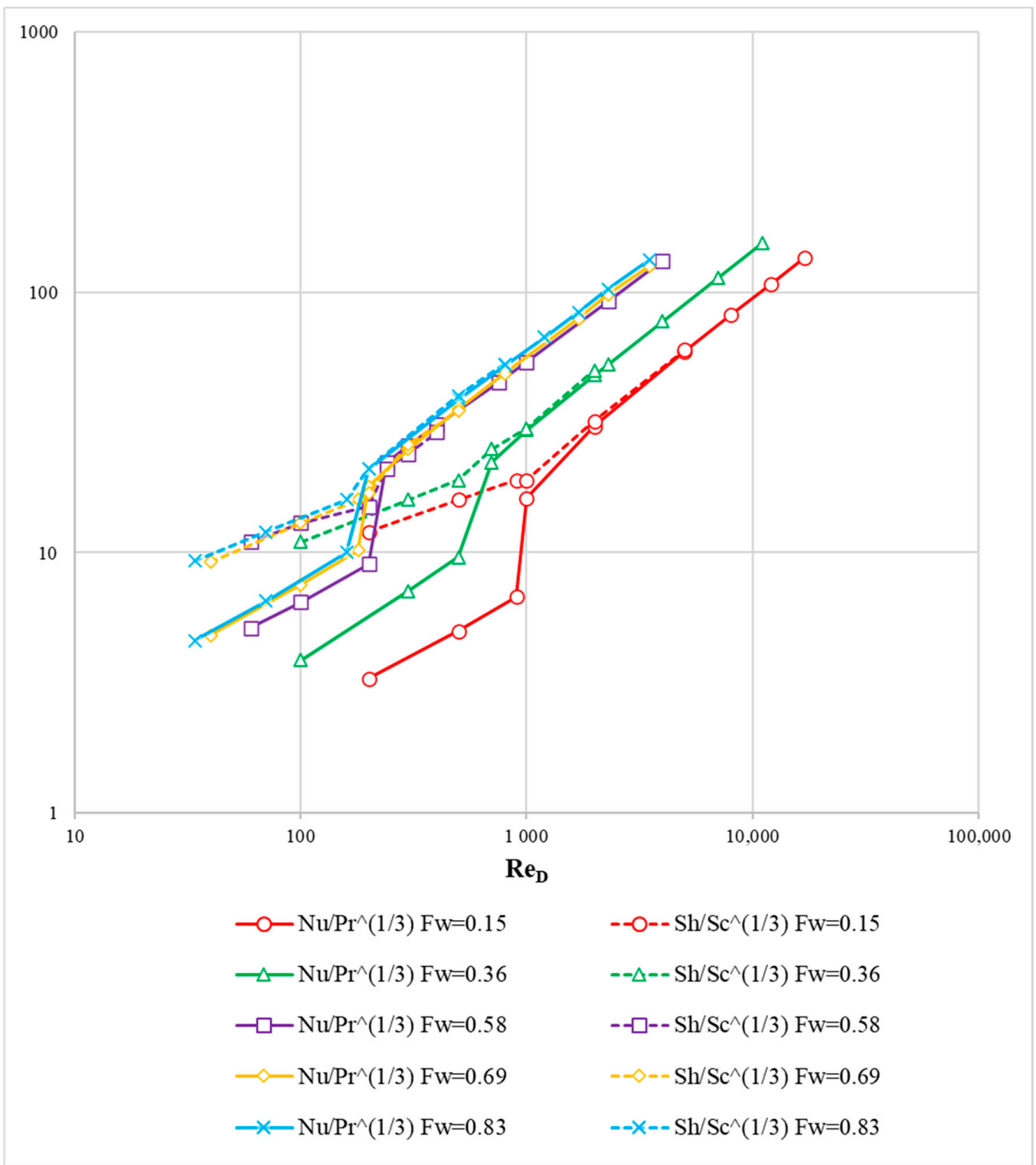

Figure 12. Comparison of heat and mass transfer phenomena in wavy-walled tubes.

Yongning et al. has reported that within the laminar flow regime the mass transfer effects in the wavy-walled tube increases with a slope of $1 / 3$ with respect to the Reynolds number as shown in Figure 12. It can be seen that heat transfer effects also increase with respect to the Reynolds number with a slope of $1 / 2$ that is higher than $1 / 3$. This suggests that the Nusselt number in wavy-walled tubes increases at a faster pace (by $50 \%$ ) compared to mass transfer effects. These results suggest that wavy-walled tubes can serve as a better heat transfer augmentation geometry for higher Prandtl number liquids. While for the turbulent flow regime, it can be observed from Figure 12 that heat and mass transfer effects show the same results with an average deviation of less than $5 \%$. Hence, it can be stated that heat and mass transfer phenomena are completely analogous in the turbulent flow regime and show nearly the same results.

Since, the flow in wavy-walled tubes becomes turbulent at an earlier Reynolds number than that of a plain tube, therefore there lies a range of Reynolds number where the flow inside a wavy-walled tube is turbulent while the flow inside a plain tube is still laminar. It is the range of Reynolds number where the Nusselt number for the wavy-walled tube is much higher, up to 45 times higher than that of the plain tube. Hence, an interesting relationship can be formed between the Nusselt number for plain 
and wavy-walled tubes $\left(N u_{w} / N u_{p}\right)$, which is shown in Figure 13 , where $N u_{w}$ is the Nusselt number for the wavy-walled tube and $N u_{p}$ is the Nusselt number for the plain tube.

Wavy-walled tubes having curved surfaces are more capable of disturbing the flow and therefore making the flow turbulent at a much lower Reynolds number compared to the plain tube. Hence higher wave factor shifts the critical Reynolds number on the lower end which results in a higher Nusselt number as shown in Figure 11. This is because the eddies in the turbulent flow help in carrying the heat and therefore turbulent flows show higher heat transfer than the laminar flow. The dependence of the critical Reynolds number on the wave factor makes an interesting range of Reynolds number where flow in the wavy-walled tube is turbulent but is still laminar in the plain tube. In that range, the Nusselt number of the wavy-walled tube is much higher due to turbulence but is still low in the plain tube due to laminar flow, hence the ratio $N u_{w} / N u_{p}$ is much higher in that range which can be seen in Figure 13. Generally, this interesting range for a particular wavy-walled tube is between the critical Reynolds number of that tube and the critical Reynolds number of the plain tube (i.e., 2300). After that range, means after $R e_{D}=2300$, the flow in the plain tube also becomes turbulent which increases its Nusselt number and therefore the ratio $N u_{w} / N u_{p}$ decreases, but of course, remains greater than one.

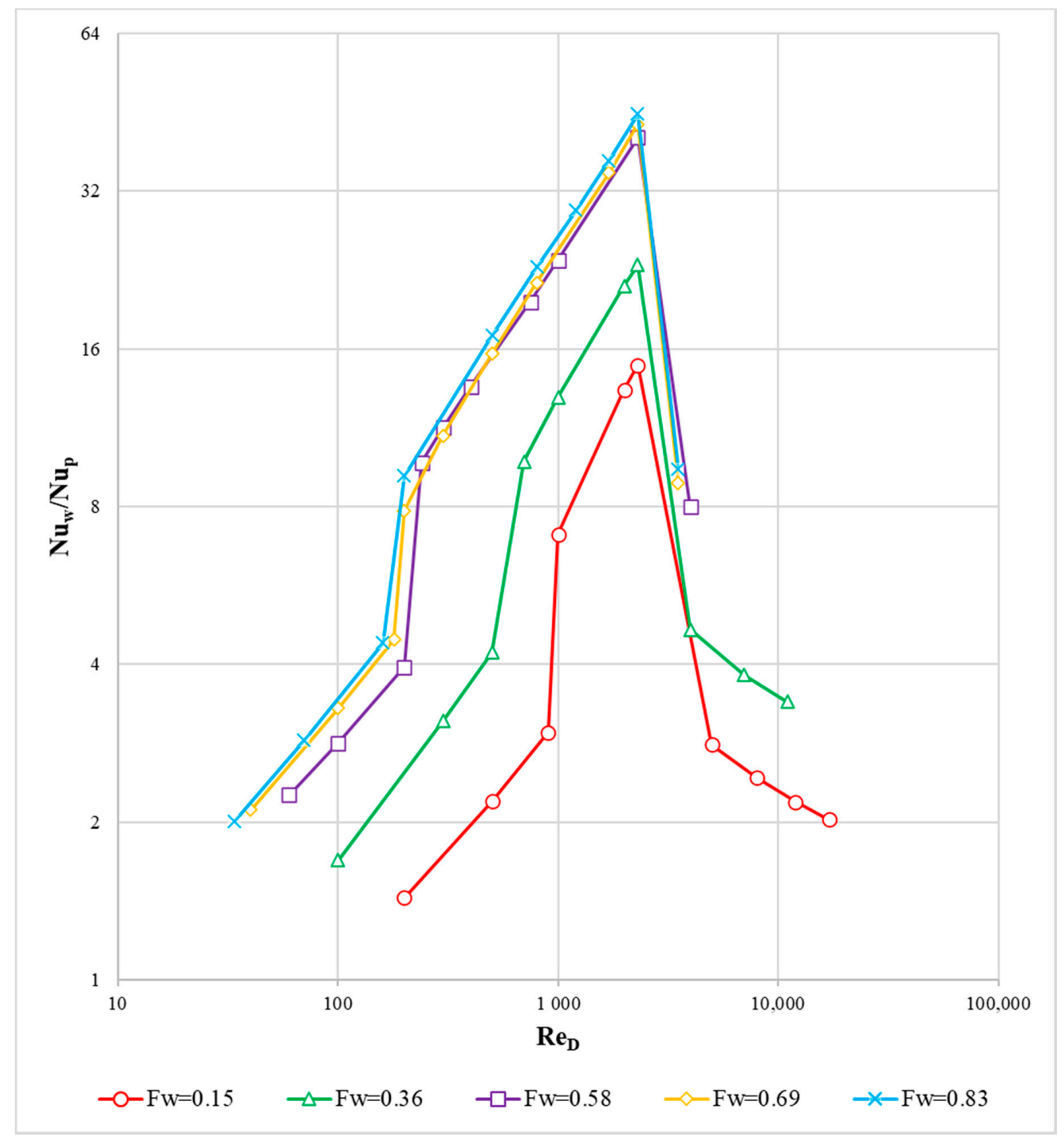

Figure 13. Heat transfer enhancement in wavy-walled tubes. 
From the hydrodynamic and thermal analysis of wavy-walled tubes, it has been observed in this paper that these tubes provide a significant amount of rise in heat transfer, but at the expense of extra pumping power. For optimization purposes, such a tube would be a better option that will provide a higher rise in Nusselt number from plain to wavy-walled tube compared to the rise in friction factor. For that purpose, a graph was formed and is shown in Figure 14. Higher values in Figure 14 represent better thermal performance with lower expense in pumping power, while lower values show a higher demand for pumping power with a little rise in heat transfer rates. According to this graph, only a tube with $F_{w}=0.15$ surpasses the value of 1 , which shows that it will be having a higher rise in Nusselt number compared to that of friction factor. Therefore, its heat transfer rates will be increased higher than the increment in pumping power. But, the tubes of high waviness (say $F_{w}=0.83$ ), which perform better for heat transfer, will also require much more pumping power. But if we only consider the thermal analysis of these tubes, of course, higher waviness in the tube surface would result in higher heat transfer rates as shown in Figures 11 and 13. So, these tubes are a good replacement to the plain tubes where compactness of the heat transfer system is a primary focus. In such scenarios, usually pumping power is a secondary matter which could have been neglected if compared with the gain in heat transfer.

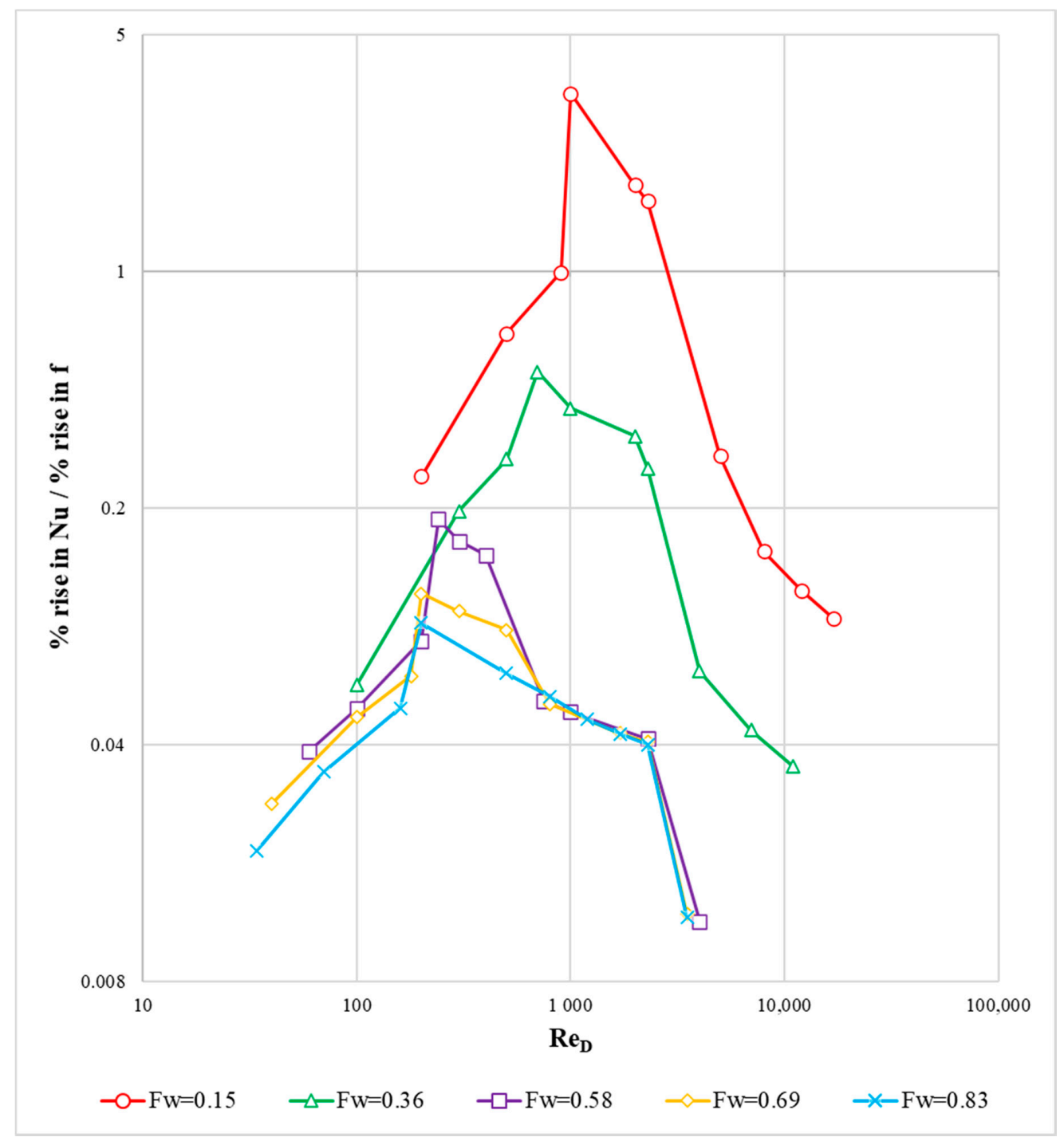

Figure 14. Relationship between thermal and hydrodynamics performance of wavy-walled tubes. 


\section{Conclusions}

The simulations for heat transfer and pressure drop in wavy-walled tubes under laminar as well as turbulent flow regime for high Prandtl number fluid was carried out using software Ansys Fluent. The computed results indicate that due to flow separation and reduced convective effects within the diverging section of the tube, the Nusselt number drops in that region, while it increases in the convergent section where velocities are higher. Therefore, the average Nusselt number of the wavy-walled tube remains higher than the plain tube for all values of the Reynolds number and all tube geometries, whether the flow is laminar or turbulent. The maximum value of the Nusselt number in the laminar flow regime was found to be 4.39 times higher than the plain tube for wave factor $F_{w}=0.83$. On the other hand, the friction factor was found to be directly proportional to the wave factor providing a rise of 67 times than that of the plain tube in laminar flow for the same wave factor.

Whereas there lies a range of Reynolds number depending on the wave factor where the flow inside the wavy-walled tube is turbulent, while for the same range of Reynolds number, the flow inside plain tube remains laminar. This is because the critical Reynolds number for the wavy-walled tube is lower than the plain tube and found to be inversely proportional to the wave factor [23]. Therefore, the Nusselt number for wavy-walled tube rises amazingly up to 45 times compared to the plain tube, for $F_{w}=0.83$. However, the friction factor rises for the wavy-walled tube. about 1096 times higher than that of the plain tube. Hence, in this range of Reynolds number, wavy-walled tubes perform significantly better in terms of heat transfer but also require high pumping power.

In the turbulent flow regime for both of the tubes, it has been found that wavy-walled tubes perform thermally better than the plain tubes but the demand in pumping power rises much more than the increment in heat transfer rates.

According to Figure 14, it can be concluded that a slight waviness $\left(F_{w}\right)$ in a tube can increase its thermal performance with a significant rise in pumping power. Since it can be observed from Figure 14 that a tube of lower wave factor $F_{w}=0.15$ has a higher percentage increase in Nusselt number than the percentage increase in friction factor. But as the waviness of the tube increases further, the percentage rise in friction factor is much greater than the percentage rise in Nusselt number. From the perspective of cost feasibility, it can be stated that tubes with lower wave factor are better, since they can provide similar heat transfer rates as plain tubes with reduced lengths but at the expense of little rise in pumping power, thereby reducing the size of the heat exchanger and lowering the cost. Although there would be a little rise in the cost of the pump and its operation, overall, the cost would eventually decrease if the cost of both, the heat exchanger and the pump are taken into account. As for the tubes with higher wave factor, it can be stated that they can thermally perform equivalent to plain tubes with many reduced lengths, hence reducing the size and purchase cost of heat exchanger even more. As for the pumping cost of such high wave factor tubes, it would go high. But if we consider the applications where the high compactness of heat exchangers is a primary concern, then the thermal performance of high wave factor tubes shows that they are a good choice.

Based on the experimental comparisons the phenomena of heat and mass transfer were found to have similar characteristics for the flow in wavy-walled tubes under laminar and turbulent flow regime. The correlations presented in this work can serve as design equations for predicting friction factor and Nusselt number for laminar and turbulent flow in wavy-walled tubes with less than $10 \%$ error.

Author Contributions: Data curation, M.S.; Formal analysis, M.M.N. and M.S.; Funding acquisition, M.M.N.; Investigation, M.M. and Z.E.; Methodology, M.M.; Validation, A.I.; Writing—original draft, M.M.N., M.S. and A.I.; Writing-review \& editing, Z.E. All authors have read and agreed to the published version of the manuscript.

Funding: This research was funded by the Universiti Brunei Darussalam's University Research Grant Number UBD/RSCH/1.3/FICBF(b)/2019/003.

Acknowledgments: The authors would like to express their deep gratitude to the NED University of Engineering and Technology for providing its support.

Conflicts of Interest: The authors declare no conflict of interest. 


\section{References}

1. Takeishi, K.-I.; Robert, K.; Yutaka, O.; Yuichi, I. Heat transfer enhancement of impingement cooling by adopting circular-ribs or vortex generators in the wall jet region of a round impingement jet. Int. J. Turbomach. Propuls. Power 2020, 5, 17. [CrossRef]

2. Beate, W.; Mark, W.; Viola, D.; Peter, J.; Micheal, R. Heat transfer in a square ribbed channel: Evaluation of turbulent heat transfer models. Int. J. Turbomach. Propuls. Power 2019, 4, 18.

3. Hatami, M.; Kheirkhah, A.; Ghanbari-Rad, H.; Jing, D. Numerical heat transfer enhancement using different nanofluids flow through venturi and wavy tubes. Case Stud. Therm. Eng. 2019, 13, 100368. [CrossRef]

4. Mehdi, S.M.; Choi, K.H. Heat Transfer Coefficient for Liquid Sodium in Developing Laminar Flow Regime. In Proceedings of the International Conference on Energy and Sustainability, Karachi, Pakistan, 1 January 2013; pp. 157-160.

5. Yang, Y.T.; Wang, Y.H.; Tseng, P.K. Numerical optimization of heat transfer enhancement in a wavy channel using nanofluids. Int. Commun. Heat Mass Transf. 2014, 51, 9-17. [CrossRef]

6. Kim, Y.J.; Kim, M.; Kim, S.; Min, J.K.; Ha, M.Y. Numerical study of fluid flow and convective heat transfer characteristics in a sinusoidal wavy circular tube. J. Mech. Sci. Technol. 2016, 30, 1185-1196. [CrossRef]

7. Sui, Y.; Teo, C.J.; Lee, P.S.; Chew, Y.T.; Shu, C. Fluid flow and heat transfer in wavy microchannels. Int. J. Heat Mass Transf. 2010, 53, 2760-2772. [CrossRef]

8. Dizaji, H.S.; Jafarmadar, S.; Mobadersani, F. Experimental studies on heat transfer and pressure drop characteristics for new arrangements of corrugated tubes in a double pipe heat exchanger. Int. J. Therm. Sci. 2015, 96, 211-220. [CrossRef]

9. Laohalertdecha, S.; Wongwises, S. The effects of corrugation pitch on the condensation heat transfer coefficient and pressure drop of R-134a inside horizontal corrugated tube. Int. J. Heat Mass Transf. 2010, 53, $2924-2931$. [CrossRef]

10. Siddiqa, S.; Hossain, M.A. Natural convection flow over wavy horizontal surface. Adv. Mech. Eng. 2013, 5, 743034. [CrossRef]

11. Sherikar, A.; Disimile, P.J. Parametric Study of Turbulent Couette Flow over Wavy Surfaces Using RANS Simulation: Effects of Aspect-Ratio, Wave-Slope and Reynolds Number. Fluids 2020, 5, 138. [CrossRef]

12. Prince, C.; Gu, M.; Peterson, S.D. A numerical study of the impact of wavy walls on steady fluid flow through a curved tube. J. Fluids Eng. 2013, 135, 071207. [CrossRef]

13. Arman, S.; Hassanzadeh, R. Effects of the geometric parameters on the thermal-hydraulic performance of the wavy tubes. Int. Commun. Heat Mass Transf. 2018, 96, 27-36. [CrossRef]

14. Jin, Z.J.; Chen, F.Q.; Gao, Z.X.; Gao, X.F.; Qian, J.Y. Effects of pitch and corrugation depth on heat transfer characteristics in six-start spirally corrugated tube. Int. J. Heat Mass Transf. 2017, 108, 1011-1025. [CrossRef]

15. Ramgadia, A.G.; Saha, A.K. Numerical study of fully developed flow and heat transfer in a wavy passage. Int. J. Therm. Sci. 2013, 67, 152-166. [CrossRef]

16. Muhammad, N.M. Adaptive boundary input heat flux and temperature estimation in a three-dimensional domain. Heat Transf. Res. 2017, 48, 239-261. [CrossRef]

17. Muhammad, N.M.; Kim, K.-Y.; Huang, C.-H.; Kim, S. Groundwater contaminant boundary input flux estimation in a two-dimensional aquifer. J. Ind. Eng. Chem. 2010, 16, 106-114. [CrossRef]

18. Nauman, M.M.; Mehdi, M.; Iqbal, A.; Abu Bakar, M.S.; Aissa, B.; Puteri, D.N.A.J.; Rafique, A.F. Adaptive state estimation of groundwater contaminant boundary input flux in a 2-dimensional aquifer. J. Groundw. Sci. Eng. 2019, 7, 373-382.

19. Pethkool, S.; Eiamsa-Ard, S.; Kwankaomeng, S.; Promvonge, P. Turbulent heat transfer enhancement in a heat exchanger using helically corrugated tube. Int. Commun. Heat Mass Transf. 2011, 38, 340-347. [CrossRef]

20. Laohalertdecha, S.; Dalkilic, A.S.; Wongwises, S. Correlations for evaporation heat transfer coefficient and two-phase friction factor for R-134a flowing through horizontal corrugated tubes. Int. Commun. Heat Mass Transf. 2011, 38, 1406-1413. [CrossRef]

21. Mehdi, S.M.; Akhtar, M.; Hussain, A.; Alothmany, D.S.; Aziz, S. CFD study of liquid sodium inside a wavy tube for laminar convectors: Effect of Reynolds number, wave pitch, and wave amplitude. Math. Probl. Eng. 2016, 2016. [CrossRef] 
22. Bian, Y.; Chen, L.; Zhu, J.; Li, C. Effects of dimensions on the fluid flow and mass transfer characteristics in wavy-walled tubes for steady flow. Heat Mass Transf. 2013, 49, 723-731. [CrossRef]

23. Yu, L.; Bian, Y.; Liu, Y.; Xu, X. Experimental analysis on fluid flow and mass transfer characteristics of CMC solutions in wavy-walled tubes for steady and pulsating flow by PIV. Appl. Therm. Eng. 2020, 171, 115098. [CrossRef]

Publisher's Note: MDPI stays neutral with regard to jurisdictional claims in published maps and institutional affiliations.

(C) 2020 by the authors. Licensee MDPI, Basel, Switzerland. This article is an open access article distributed under the terms and conditions of the Creative Commons Attribution (CC BY) license (http://creativecommons.org/licenses/by/4.0/). 